\title{
Penetrating gunshot wound, emphysema and inanition followed by death in a wild Asian elephant:
} \section{a case report}

\begin{abstract}
A 10-years-old male wild Asian elephant (Elephas maximus) was rescued by Bangladesh Forest Department at Rangamati Lake, Chittagong with the history of inanition and generalized emphysema. The left eye was blind and three gunshot wounds were diagnosed at head and neck region through physical examination followed by general anesthesia. Each wound was penetrating in nature and more than 12 inch deep on probe detection. There developed pharyngeal paralysis from gunshot wound and so grasped foods were dropped from the mouth. Fecal examination revealed absence of parasitic infection while chronic anemia was detected from laboratory report. The elephant was treated with antibiotic, steroid drug and fluid therapy for 12 days. The emphysematous condition was improved after using steroids and antibiotics without improving appetite. Fluid therapy was continued as a maintenance dose to defend dehydration. The Elephant became weaker gradually due to starvation and finally died at 12th day of treatment. At postmortem examination, two bullets were found at the frontal sinus and another one at pharyngeal region. The study concluded that gunshot induced pharyngeal injury followed by pharyngeal paralysis gave rise in off-feeding which ascertained the death of the elephant.
\end{abstract}

Keywords: asian elephant, pharyngeal paralysis, gunshot, emphysema, penetrating wound
Volume 3 Issue 2 - 2018

\author{
Bibek Chandra Sutradhar,' Bhajan \\ Chandra Das,' Sabrina Ferdous,' Mustafiz \\ Rahman, ${ }^{2}$ Sayed Hossain, ${ }^{3}$ Farhad Hossain, ${ }^{4}$ \\ Hasanuzzaman ${ }^{5}$ \\ 'Department of Medicine and Surgery, Chittagong Veterinary and \\ Animal Sciences University, Bangladesh \\ ${ }^{2}$ Bangabandhu Sheikh Mujib Safari park, Bangladesh \\ ${ }^{3}$ Wildlife and Nature Conservation Division, Bangladesh \\ ${ }^{4}$ Artificial Insemination Center, Bangladesh \\ ${ }^{5}$ Department of Animal Science and Nutrition, Chittagong \\ Veterinary and Animal Sciences University, Bangladesh
}

Correspondence: Bibek Chandra Sutradhar, Department of Medicine and Surgery, Chittagong Veterinary and Animal Sciences University, Chittagong, Bangladesh, Tel 88031659 093(EX-109/294), 8803 1659620,Email bibeksd@yahoo.com

Received: February 09, 2018 | Published: March 15, 2018
Abbreviations: CHT, Chittagong Hill Tracts; IUCN, International Union for Conservation of Nature

\section{Introduction}

Asian elephant (Elephas maximus) are the largest herbivorous mammals of the world, which is now enlisted as critically endangered species in Bangladesh. Asian elephants were most abundant in the south-eastern part of Bangladesh namely Chittagong Hill Tracts (CHT), but now a days the number of these elephant has declined due to human settlement in the hilly areas that causes the habitat destruction as well as reduction of food availability for them Gunshot is very frequent/common phenomena in hilly forest areas of the country where conflicts take place between local peoples and elephants. Usually elephants are encountered to gunshot and killed when they attack on human or come to the locality in search of food and destroy crops as well as houses. Apart from, illegal poaching of the species for their ivory, skin or meat is another reason of killing elephant. ${ }^{1-3}$ With the increase of modern firearms and their widespread access, illegal hunting and gunshot wounds are in rise to the field which bringing about tremendous risk to the animal's health and life. Generally, firearms like handguns, hunting rifles or shotguns are used legally or illegally to hunt or kill animals silently with no time. Domestic as well as wild birds and mammals are the victim of the accidental or deliberate shooting where death is the most usual outcome. ${ }^{4-6}$ Gunshot wound has been reported before in different species of wild and domesticated animals or pet. ${ }^{7-10}$ Therefore the case report is presenting the management and treatment of gunshot wound induced emphysema and inanition as well as post mortem confirmation of the findings.
Gunshot wound is a punctured wound can be defined as penetration of the body by a bullet or projectiles, characterized by formation of channel either having both entrance and exit (when perforating) or only having the entrance without exit (penetrating) and sometimes only having the contact. Exposure of the wound to the external environment (through opening) and debris carried by projectiles inside to the body may lead to secondary bacterial infection to the injured animals. Post exposure complications depend on some factors like characteristics of gun and ammunition, speed of the bullet, distance and angle of gunshot and properties of tissues and organ of the body wounded or injured. ${ }^{5,6,11-13}$ Diagnostic gunshot marks are the leading signs of gunshot wounds while some other signs or symptoms like pain, hemorrhage, generalized edema, and constitutional disturbance may found. The external prominent signs of a penetrating gunshot wound are generally manifested enough but sometimes it is quite difficult to diagnose the actual nature and extent of gunshot wound. ${ }^{14}$ It is necessary to adopt imaging techniques (X-ray, ultrasound, CT scan etc.) to determine the distribution or placement of bullets ${ }^{4}$ which will assist with further treatment. Puncture of parts of the respiratory or gastrointestinal_systems may induce subcutaneous emphysema. In situations of penetrating trauma such as gunshot wounds or stab wounds, air may become trapped in the thoracic region. Necrotising skin infection (e.g. gas gangrene) in injured part of the body can produce gas that usually entrapped within the subcutaneous tissues that gives rise in generalized emphysema. ${ }^{15,16}$ Inanition is an important presenting sign of gunshot wound in which exhausted state developed in injured animal due to prolonged under-nutrition or starvation. It may have a major contribution to increase morbidity and mortality. Gunshot wound along with emphysema and inanition is very rare in 
elephant. As per authors' knowledge, this is the first report on gunshot wound associated with emphysema of elephant in Bangladesh.

\section{Case presentation}

A 10-years-old exhausted wild male Asian elephant (Elephas maximus) was rescued by Bangladesh Forest Department at Rangamati Lake, Chittagong. The elephant was unable to take any food and water orally from the beginning of rescued. To facilitate restraining and physical examination, anesthesia was performed with Xylazine and Ketamine (each 350mg) intramuscularly without premedication. After 15 minutes the elephant was anaesthetized fully and the condition persisted for 100 minutes without any complications. The weight of the elephant was approximately $3000 \mathrm{~kg}$.On first day of examination body temperature of the elephant was found normal $\left(98^{\circ} \mathrm{F}\right)$; generalized emphysema (Figure 1) with three penetrating wounds was detected. The left eye was blind without any injury. Three penetrating gunshot wounds were diagnosed through physical examination with two on the forehead and one behind the left ear. Each wound was penetrating in nature and more than 12 inch in depth detected by a probe (Figure 2). The elephant had the tendency to eat but grasped foods were dropped from the mouth. No parasites were found on fecal examination however, chronic anemia was detected from blood analysis in laboratory. Generalized emphysema was minimized after three days treatment with corticosteroid $(0.04 \mathrm{mg} /$ $\mathrm{kg}$ ) and long acting Oxytetracycline $\left(15 \mathrm{mg} / \mathrm{kg}\right.$, IM). Vitamin $\mathrm{B}_{1}$ and $\mathrm{B}_{12}$ were used as an adjunct treatment (Figure 3). Fluid therapy ( $5 \%$ dextrose) was continued $(15,000-20,000 \mathrm{ml} /$ day) to check the dehydration. Oxytetracycline was replaced with Ceftriaxone $(7 \mathrm{mg} /$ $\mathrm{kg}$ ) for the following seven days. The elephant gradually became weaker due to starvation and finally died after 12 days of treatment. After postmortem examination two bullets were found within the frontal sinus and one beside the pharynx (Figure 4). The dead body was buried at the bank of Kaptai Lake after collection of its ivory.

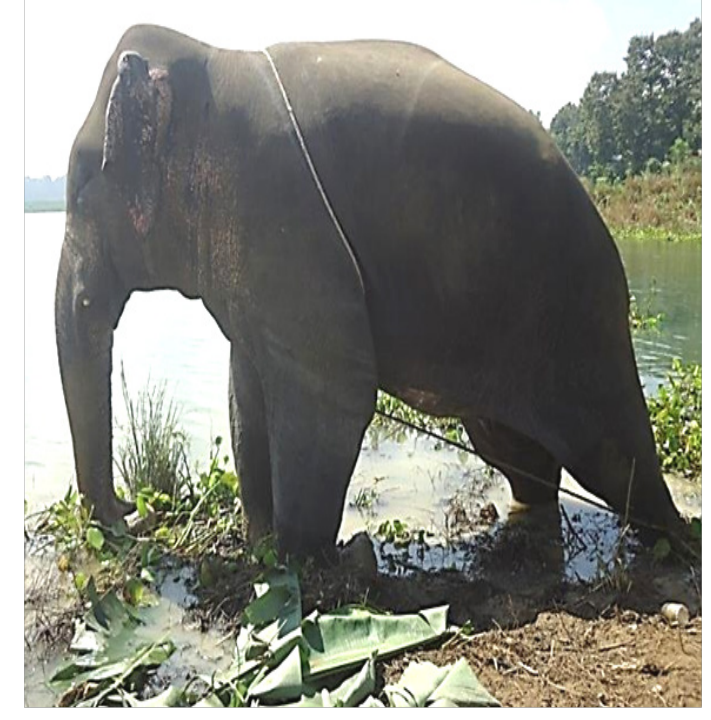

Figure I Emphysema was detected at the Day-I of rescue.

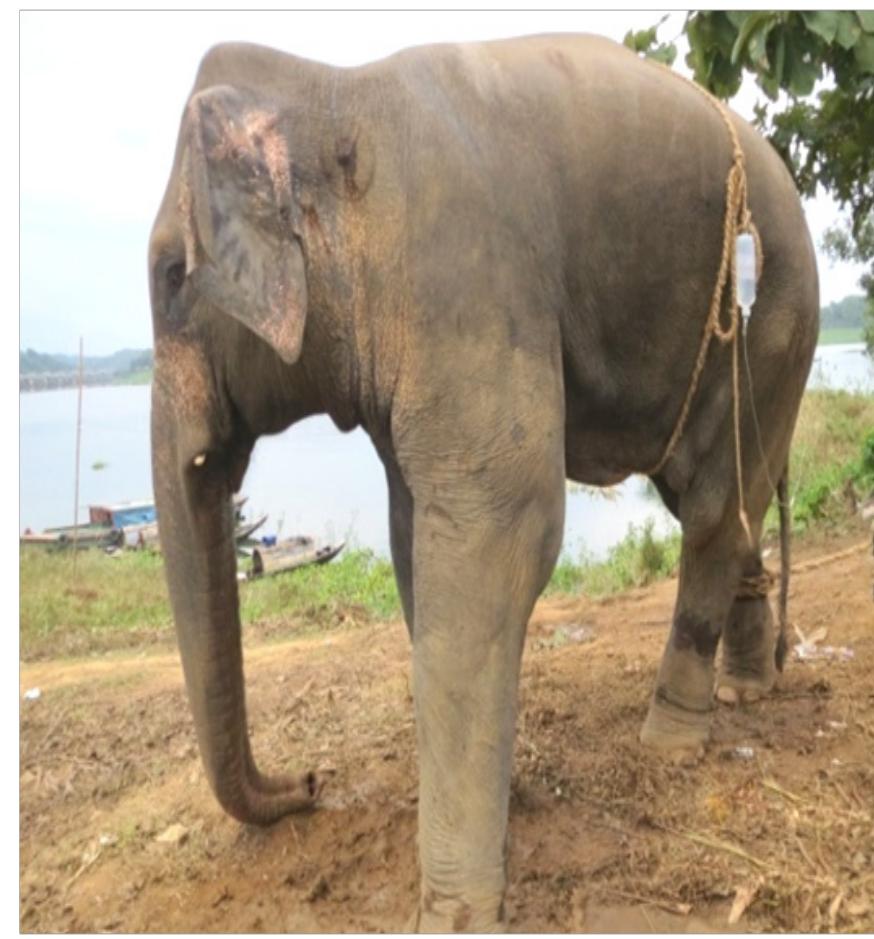

Figure 2 The elephant was cured from emphysema on Day-4 of the rescue.

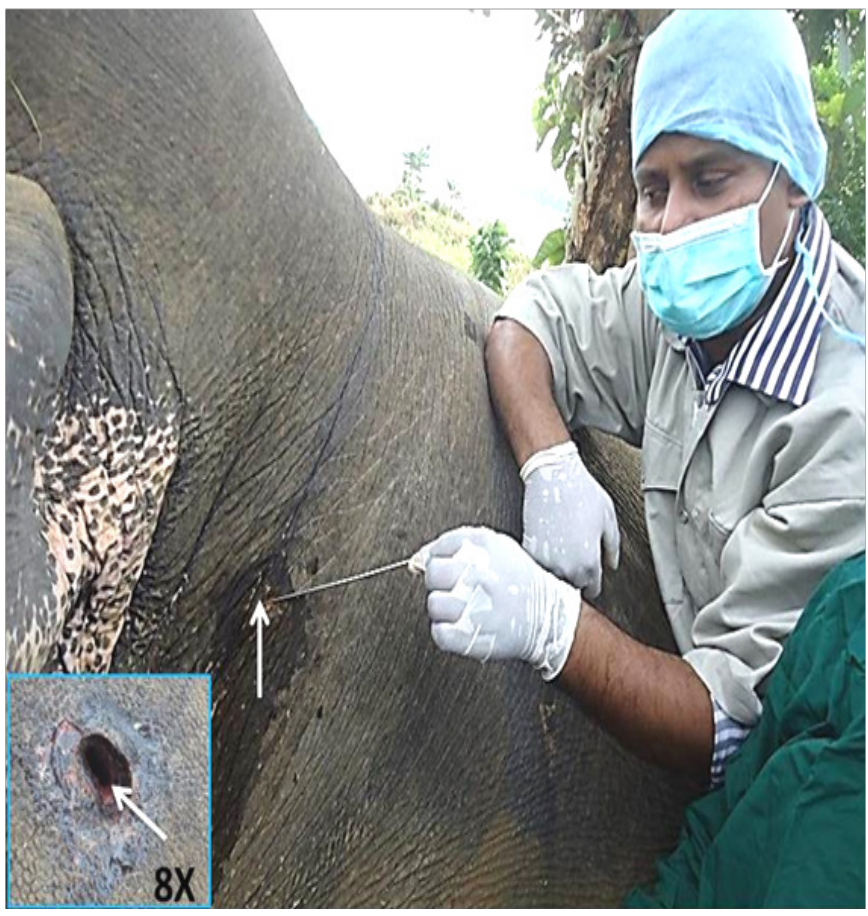

Figure 3 Probing of gunshot wound (arrow marked) to detect the depth of the wound in neck which was measured more than 12 inches. 


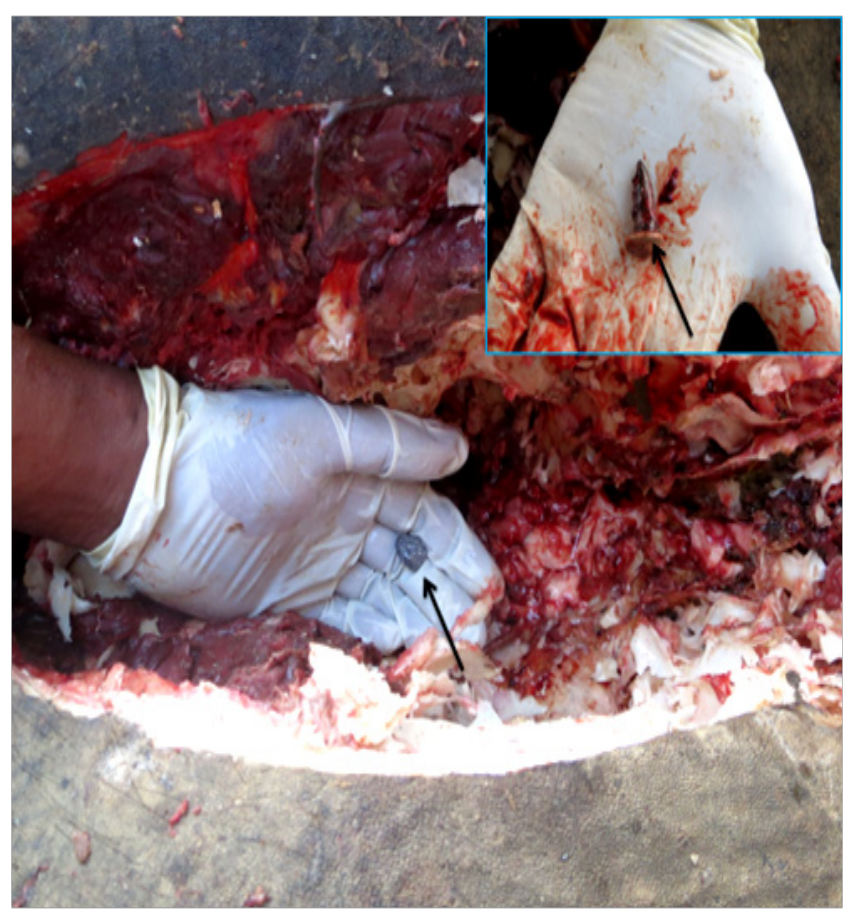

Figure 4 Bullets were found (arrow marked) at postmortem examination of the elephant.

\section{Discussion and conclusion}

The elephant was died due to lack of energy from the off-feeding induced by pharyngeal paralysis from gunshot injury. Pharyngeal paralysis is a complicated issue when it comes up with major clinical signs or complication such as dysphagia. In the gunshot wound of pharynx, the penetration of the bullet can cause both blood vessels as well as nerves to be severed, sheared, torn, crushed, or otherwise damaged. This usually results in loss of function of the pharynx that called pharyngeal paralysis. Nature of the wound, extent of the injury, relative position of the wound on pharynx, determines whether the injury is complete or incomplete. Complete injuries e.g. perforating gunshot wound may result in total loss of function or complete paralysis of the pharynx, while incomplete injuries e.g. penetrating gunshot wound may result in some degree of function loss or incomplete/ partial pharyngeal paralysis. ${ }^{17}$ In this case, bullet entered and hit the pharyngeal region from right side and damaged both blood vessels as well as nerves of that region which leaded off to pharyngeal paralysis. This pharyngeal paralysis further acted as an initiator to the inanition followed by starvation which was another factor responsible for the death of the elephant. The elephant was not able to eat food and the grasped foods were dropped from the mouth indicted the dysphagia developed from pharyngeal paralysis. Due to consistent off feeding, the elephant became weak gradually, which aggravated the anemic condition and potentiated the rate of mortality.

Some literature stated that, gunshot induced penetrating head injuries proceed high mortality in dogs and humans with some obvious signs like as contra-lateral blindness, facial paralysis, seizure, drooping head etc. ${ }^{8,18,19}$ In the current case, two bullets that were entered through forehead and embedded in the frontal sinus, was the probable cause of blindness of the left eye. Although, there was no external bleeding however internal bleeding along with blood and blood clots were revealed in postmortem examination. Internal bleeding which might have crucial role in death of small pet animals. ${ }^{5}$ Accidentally, chronic or persistent internal or external bleeding may facilitate in hemorrhagic anemia followed by death. Gunshot injury along with other traumatic injuries or complications such as emphysema, pain, bone fractures, lethargy, paralysis, pneumo-thorax and internal hemorrhage may threaten the survival of injured animals. Death is ineluctable in case of severe injury in major organs e.g. brain. ${ }^{5}$ Some cases reported that animals got survived due to early diagnosis, proper treatment and less severity of injury. ${ }^{7-10}$ Gunshot wounds require the surgical treatment to remove the existing bullet as well as necrotic tissues from the animal's body. Antibiotic and antiinflammatory drugs are widely used to treat the gunshot wound. ${ }^{6,20}$ Antibiotic therapy is usually provided to combat secondary bacterial infection. The role of antibiotics in gunshot injuries has been widely debated..$^{21,22}$ To defeat emphysema corticosteroid drugs are widely used that was followed in this case study.

Elephant killing for meat as well as for ivory is common scenario in Africa; however in Bangladesh, it is occurring behind our eyes which might be a great threat to the Elephant conservation. This report will warn with a view to supporting animal welfare and will give a spot light on the hidden activities of few tribal peoples living near the forest. These illegal activities only may control by implementing an effective law from the government and counseling with the local peoples to motivate them. It is dire need to make them understand, the importance of the forest and elephant in Bangladesh for the betterment of ecology and human-health.

\section{Acknowledgements}

Authors acknowledge to the Department of Forest, Rangamati, Chittagong, Bangladesh for their best support and co-operation.

\section{Conflict of interest}

The authors have neither financial interest nor conflicts of interest related to research in this article.

\section{References}

1. Islam MA, Mohsanin S, Chowdhury GW, et al. Current status of Asian elephants in Bangladesh. Gajah. 2011;(35):21-24.

2. Motaleb M, Rahman S, Rahman S, et al. The Asian Elephants and Associated Human-elephant Conflict in South-Eastern Bangladesh. IUCN, Bangladesh; 2011.

3. Raihan Sarker A, Røskaft. Human-wildlife conflicts and management options in Bangladesh, with special reference to Asian elephants (Elephas maximus). IJBSESM. 2010;6(3-4):164-175.

4. Frost PA, Grier RL. Management of gunshot wounds. Iowa State University Veterinarian. 1985;47(2):133-135.

5. Alcigir ME, Vural SA, Alcigir G. Evaluation of Patho-morphological Changes Associated with a Firearm Injury in Terms of Wound Ballistic in a Dog. RJVP. 2014;2(5):78-81.

6. Felsmann M, Felsmann M, Babińska J, et al. A Review of Firearms, Projectile and Gunshot Wounds in Animals. PVJ. 2014;34(3):279-287.

7. Nath I, Pattanaik T, Sahoo N, et al. Management of gun-shot wounds in a Sloth Bear Melursus ursinus. ZPJ. 2007;22(6):2734-2735. 
8. Park S, Park J, Kim J, et al. Penetrating cranial injury due to gunshot in a dog: a case report. Veterinarni Medicina. 2010;55(5):253-257.

9. Shrivastava A, Shargava M, Singh R, et al. Gun Shot Wounds in a Crocodile (Crocodylus palustris) and its Management. Intas Polivet 2011;2(2):170-171.

10. Kumar V. Management of gunshot bullet in a rescued leopard (Panthera pardus). IJAVS. 2013;(1):91-93.

11. Clasper J. The interaction of projectiles with tissues and the management of ballistic fractures. J R Army Med Corps. 2001;147(1):52-61.

12. Von See C, Stuehmer A, Gellrich N, et al. Wound ballistics of injuries caused by handguns with different types of projectiles. Mil Med. 2009;174(7):757-761.

13. Elias P. Wound ballistics: analysis of blunt and penetrating trauma mechanisms. HSJ. 2010;4(4):225-236.

14. Longmore T. A Treatise on gunshot wounds. JB Lippincott. 1862;(840).

15. Maunder RJ, Pierson DJ, Hudson LD. Subcutaneous and mediastinal emphysema: pathophysiology, diagnosis, and management. Arch Intern Med. 1984;144(7):1447-1453.

16. Tumram NK, Bardale RV, Dixit PG, et al. Fatal subcutaneous emphysema by manja: a deadly string. BMJ case reports. 2013;bcr2012007727.

17. Hanlon D, Srivastava A, Menaker J. Gunshot Wounds: Management and Myths. Trauma Reports. 2012;13(1):1-11.

18. Bebchuk TN, Harari J. Gunshot injuries: pathophysiology and treatments. SAP. 1995;25(5):1111-1126.

19. Shimura T, Mukai T, Teramoto A, et al. Clinicopathological studies of craniocerebral gunshot injuries. No shinkei geka. 1997;25(7):607-612.

20. Aithal H. Gunshot wound in a dog and its management. IJCPV. 2014;6(2):154.

21. Dicpinigaitis PA, Koval KJ, Tejwani NC, et al. Gunshot wounds to the extremities. Bulletin-hospital for joint diseases. 2006;64(3/4):139-155.

22. Simpson BM, Wilson RH, Grant RE. Antibiotic therapy in gunshot wound injuries. Clin Orthop Relat Res. 2003;(408):82-85. 